\title{
Hypoxia-induced Paracrine Regulation of Vascular Endothelial Growth Factor Receptor Expression
}

\author{
Edi Brogi,, ${ }^{\star}$ Gina Schatteman, ${ }^{\star}$ Tiangen Wu, ${ }^{\star}$ Elizabeth A. Kim, ${ }^{\star}$ Lyuba Varticovski, ${ }^{\ddagger}$ Bruce Keyt, ${ }^{\S}$ and Jeffrey M. Isner` \\ Department of Medicine $\left({ }^{*}\right.$ Cardiology and ${ }^{\ddagger}$ Hematology) and Biomedical Research, St. Elizabeth’s Medical Center, Tufts University \\ School of Medicine, Boston, Massachusetts 02135; and ${ }^{\S}$ Genentech Inc., South San Francisco, California
}

\begin{abstract}
Vascular endothelial growth factor (VEGF)/vascular permeability factor (VPF), an endothelial cell (EC)-specific mitogen, stimulates angiogenesis in vivo, particularly in ischemic regions. VEGF/VPF expression by cells of hypoxic tissues coincides with expression of its two receptors, KDR and flt-1, by ECs in the same tissues. We investigated whether hypoxia or hypoxia-dependent conditions operate in coordinating this phenomenon. Human umbilical vein and microvascular ECs were exposed to direct hypoxia or to medium conditioned (CM) by myoblasts maintained in hypoxia for $4 \mathrm{~d}$. Control ECs were maintained in normoxia or normoxia-CM. Binding of ${ }^{125}$ I-VEGF to ECs was then evaluated. Hypoxic treatment of ECs had no effect on ${ }^{125}$ I-VEGF binding. However, treatment of ECs with hypoxia-CM produced a threefold increase in ${ }^{125}$ I-VEGF binding, with peak at $24 \mathrm{~h}(P<0.001$, ANOVA). Scatchard analysis disclosed that increased binding was due to a 13-fold increase in KDR receptors/cell, with no change in $\mathrm{KDR}$ affinity $\left(K_{d}=260 \pm 51\right.$ pM, normoxia-CM versus $K_{d}=281 \pm 94 \mathrm{pM}$, hypoxia-CM) and no change in EC number $\left(35.6 \pm 5.9 \times 10^{3} \mathrm{ECs} / \mathrm{cm}^{2}\right.$, normoxia-CM versus $33.5 \pm 5.5 \times 10^{3} \mathrm{ECs} / \mathrm{cm}^{2}$, hypoxia-CM). Similar results were obtained using $\mathrm{CM}$ from hypoxic smooth muscle cells. KDR upregulation was not prevented by addition to the hypoxia-CM of neutralizing antibodies against VEGF, tumor necrosis factor- $\alpha$, transforming growth factor $\beta 1$ or basic fibroblast growth factor. Similarly, addition of VEGF or lactic acid to the normoxia-CM had no effect on VEGF binding. We conclude that mechanism(s) initiated by hypoxia can induce KDR receptor upregulation in ECs. Hypoxic cells, normal or neoplastic, not only can produce VEGF/VPF, but can also modulate its effects via paracrine induction of VEGF/VPF receptors in ECs. $(J$. Clin. Invest. 1996. 97:469-476.) Key words: ischemia • angiogenesis • endothelial cells $・ \mathrm{KDR} \cdot$ flt-1
\end{abstract}

Address correspondence to Jeffrey M. Isner, M.D., Division of Cardiology, St. Elizabeth's Medical Center, 736 Cambridge St., Boston, MA 02135. Phone: 617-789-2392; FAX: 617-789-5029; E-mail: jisner @opal.tufts.edu

Received for publication 7 June 1995 and accepted in revised form 2 October 1995.

1. Abbreviations used in this paper: $\mathrm{bFGF}$, basic fibroblast growth factor; CM, conditioned medium; HMECs, human microvascular endothelial cells; M199, medium 199; SMCs, smooth muscle cells; VEGF/ VPF; vascular endothelial growth factor/vascular permeability factor.

J. Clin. Invest.

(C) The American Society for Clinical Investigation, Inc.

0021-9738/96/01/469/08 \$2.00

Volume 97, Number 2, January 1996, 469-476

\section{Introduction}

Vascular endothelial growth factor $(\mathrm{VEGF})^{1}(1) /$ vascular permeability factor (VPF) $(2,3)$ is a potent endothelial cell mitogen in vitro $(1,3)$ and a potent permeability mediator $(2,3)$ and angiogenic growth factor in vivo $(3,4)$. VEGF/VPF, hereafter referred to as VEGF, is a homodimeric glycoprotein found as four isoforms, generated by alternative splicing from a single gene (5). Two specific VEGF receptors located exclusively on endothelial cells (ECs) have been identified to date. They are KDR (6) and flt-1 (7), both tyrosine-kinases that autophosphorylate in response to VEGF stimulation (6-8).

VEGF appears to play a role in hypoxia-related angiogenesis occurring during wound healing (9), proliferative retinopathy $(10)$, revascularization of ischemic areas $(11,12)$ and tumor progression (13-16). In addition to hypoxia-induced expression of VEGF $(13,17,18)$, various investigators have also documented in vivo increased expression of its receptors in pathologic conditions characterized by hypoxia. For example, ECs of tumor vessels but not of normal tissues, express VEGF receptors (14-16). Although a solid neoplasm is richly vascularized, the combination of rapid tumor growth and interstitial edema due to the highly permeable vasculature result in conditions of local hypoxia $(19,20)$. Increased production of VEGF by keratinocytes during wound healing (9) also parallels increased expression of VEGF receptors on neovessels of healing wounds (21). Interestingly, low oxygen tension characterizes the central portion of a wound, due to disruption of the local vasculature (22). Furthermore, systemic administration of VEGF in a rabbit ischemic hindlimb model, causes selective revascularization of the ischemic but not of the normally vascularized areas of the limb (23). The localized biological effects observed in this experimental model imply that local expression of VEGF receptors might be increased. All these findings suggest that hypoxia-dependent local factors might regulate angiogenesis not only via induction of VEGF, but also via concomitant induction of specific VEGF receptors on ECs, therefore selectively targeting maximal angiogenesis to oxygen deprived areas.

To test this hypothesis, we evaluated the effects of low oxygen tension on binding of recombinant human ${ }^{125}$ I-VEGF to human ECs in vitro. Direct exposure of ECs to hypoxia did not affect ${ }^{125} \mathrm{I}-\mathrm{VEGF}$ binding. However, treatment of ECs with conditioned medium (CM) obtained from hypoxic myoblasts or smooth muscle cells upregulated the specific binding of ${ }^{125}$ I-VEGF to ECs. The increased binding of ${ }^{125} \mathrm{I}-\mathrm{VEGF}$ to ECs was due to increased number of KDR receptors expressed by these cells, rather than to a change in the receptor's affinity.

These data indicate that ischemic tissues may release and/ or produce soluble "factor(s)" capable of locally upregulating VEGF receptor expression on ECs and thereby promote local neovascularization. These observations extend the conceptual 
basis for mechanisms which control hypoxia-dependent angiogenesis.

\section{Methods}

Reagents. All reagents used were obtained from Sigma Chemical Co. (St. Louis, MO), unless otherwise stated. Human recombinant basic fibroblast growth factor (bFGF) and platelet derived growth factor BB (PDGF BB) were obtained from Genzyme Corp. (Cambridge, MA).

Cell culture. Human umbilical vein (HUV) ECs were isolated according to the method of Jaffe et al. (24), plated onto $1.5 \%$ gelatincoated wells and grown in medium 199 (M199) (GIBCO BRL, Gaithersburg, MD) with $20 \%$ fetal bovine serum (FBS) (GIBCO BRL), endothelial cell growth supplement $(100 \mu \mathrm{g} / \mathrm{ml})$ and heparin $(50 \mathrm{U} / \mathrm{ml})$. HUVECs were used between passage 1 and 5. Human microvascular (HM) ECs of dermal origin were purchased from Clonetics Corp. (San Diego, CA), grown in EBM medium containing human epidermal growth factor $(10 \mathrm{ng} / \mathrm{ml})$, hydrocortisone $(10 \mathrm{mg} / \mathrm{ml}), 5 \%$ FBS and $0.4 \%$ bovine brain extract (Clonetics Corp.). HMECs were used between passages 4 and 6 .

L6 cells, a methyl cholantrene-transformed rat myoblast cell line purchased from American Type Culture Collection (Rockville, MD), were grown in DME $+10 \%$ FBS and used between passages 6 and 8 . Human vascular smooth muscle cells (SMCs) were isolated from segments of internal mammary arteries obtained at bypass surgery (St. Elizabeth's Medical Center) and grown as previously described (25). SMCs were used between passages 3 and 5 .

Northern blot analysis. Extraction of total RNA and Northern blot analysis were performed as previously reported (17). The DNA probes were: for human KDR, a 709-bp EcoRI-HindIII fragment (gift of B.Terman, American Cyanamid, NJ); for human flt-1, a 417-bp KpnI-HindIII fragment (gift of L. T. Williams, UCSF, CA); for human VEGF, a 675-bp EcoRI-BglII fragment (gift of N. Ferrara, Genentech Inc., CA); for $\beta$-actin, a 1.5-kb EcoRI fragment of plasmid HFBCC49, purchased from the American Type Culture Collection. Probes were radiolabeled using a random primed DNA labeling kit (Boehringer Mannheim, Indianapolis, IN) to specific activities of $1-10 \times 10^{8} \mathrm{cpm} / \mu \mathrm{g}$.

Identification of functional VEGF receptors on HUVECs. To verify that functional VEGF receptors were present in ECs in our cultures, phosphorylated forms of KDR and flt-1 were identified. HUVECs were incubated overnight in M199 + 1\% BSA and stimulated for $10 \mathrm{~min}$ with VEGF $(100 \mathrm{ng} / \mathrm{ml})$. Lysis of cells, immunoprecipitation and Western immunoblot analysis were performed according to published methods (26). Briefly, aliquots of protein extracts $(1 \mathrm{mg})$ were incubated with an anti-phosphotyrosine monoclonal antibody (UBI, Lake Placid, NY) for $3 \mathrm{~h}$ at $4{ }^{\circ} \mathrm{C}$, followed by incubation with Protein A-Sepharose beads for $40 \mathrm{~min}$ at $4^{\circ} \mathrm{C}$. Beads were washed with immunoprecipitation buffer followed by four washes with PBS (26). Immunoprecipitates of tyrosine-phosphorylated proteins were separated by $8.75 \%$ SDS-PAGE and transferred to nitrocellulose filters. The membranes were immunoblotted with an affinity-purified anti-KDR rabbit polyclonal antibody (1:2000) (gift of B. Terman; American Cyanamid, Wayne, NJ) and an affinity-purified rabbit polyclonal anti-human flt-1 antibody $(0.5 \mu \mathrm{g} / \mathrm{ml})$ (Santa Cruz Biotechnology, Santa Cruz, CA) for $3 \mathrm{~h}$ at room temperature. Blots were washed with $0.1 \%$ Tween 20-PBS (TPBS) for $1 \mathrm{~h}$ and incubated with a peroxidase-linked goat anti-rabbit antibody (1:10000) for 45 min. After extensive washing with TPBS and a final wash with PBS alone, immunoreactive bands were visualized using ECL reagent (Amersham Corp., Arlington Heights, IL).

Hypoxia. To expose cells to conditions of low oxygen tension, cell plates were arranged in air chambers (Billups-Rothenberg) constructed with inflow and outflow valves. A pre-analyzed air mixture $\left(95 \% \mathrm{~N}_{2}+5 \% \mathrm{CO}_{2}\right.$; AIRCO) was infused into the air chambers at a flow rate of 3 liters/min for $15 \mathrm{~min}$ twice a day (17). The $\mathrm{pO}_{2}$ measured with a gas analyzer (278 Blood gas Systems, Ciba-Corning Di- agnostics Corp.), reached a nadir of $35 \mathrm{mmHg}$ in the culture medium about $6 \mathrm{~h}$ after the infusion was completed and persisted at 24 and $48 \mathrm{~h}$.

Exposure of ECs to low oxygen tension. We investigated whether hypoxia could modify the expression of VEGF receptors on ECs. To this purpose HUVECs (four experiments) were exposed to low oxygen tension for 1, 4, 6, and $24 \mathrm{~h}$. HMECs were exposed to hypoxia for $1,3,7$, and $24 \mathrm{~h}$. Control ECs were maintained in normoxia and evaluated at corresponding time points. Fresh HUVEC or HMEC culture medium or DME $+1 \%$ BSA $+1 \%$ FBS $(5 \mathrm{ml} / 100 \mathrm{ml}$ plate $)$ were used for these experiments. ${ }^{125}$ I-VEGF binding to ECs exposed to direct hypoxia or control ECs was assessed as described below (binding assay and analysis).

Generation of hypoxia-conditioned medium by muscle cells. To determine if hypoxic cells, located in proximity to ECs in vivo, could influence VEGF receptor expression by production and/or release of soluble factor (s), ECs were treated in vitro with medium conditioned by hypoxic muscle cells. These experiments are referred to as "indirect" hypoxia. Rat myoblasts or human SMCs were maintained in hypoxia or normoxia for $4 \mathrm{~d}$ without medium change (DME $+10 \%$ FBS; $2.5 \mathrm{ml} / 100 \mathrm{~mm}$ plate). Pooled media were then spun $(3200 \mathrm{~g}, 10$ $\min , 4^{\circ} \mathrm{C}$ ), sequentially passed through 0.45 and $0.2 \mu \mathrm{m}$ sterile filters, and used immediately or stored at $-80^{\circ} \mathrm{C}$ for up to $1 \mathrm{wk}$. $\mathrm{pH}$ and lactic acid concentration (lactic dehydrogenase enzymatic assay; Smith Kline Clinical Laboratories, Waltham, MA) of normoxia- and hypoxia-CM were determined before treatment of ECs.

Treatment of ECs with muscle cell conditioned medium. Before each "indirect" hypoxia experiment, ECs were washed twice with PBS and starved overnight in DME $+1 \%$ BSA $+1 \%$ FBS, to maintain similar basal levels of receptor expression. HUVECs (four experiments) or HMECs (two experiments) were treated for 1, 4, 7, 16, 24, or $48 \mathrm{~h}$ with CM and VEGF binding to ECs determined as described below (binding assay and analysis). In two separate experiments, hypoxia-CM was serially diluted with normoxia-CM $(1: 2,1: 4,1: 10 ; 1: 20$ dilutions) or heat-inactivated at $95^{\circ} \mathrm{C}$ for $30 \mathrm{~min} ;{ }^{125} \mathrm{I}-\mathrm{VEGF}$ binding was then assessed at $24 \mathrm{~h}$ of treatment. For Northern analysis, HUVECs were starved overnight, then treated with medium conditioned in hypoxia or normoxia by rat myoblasts. Total RNA was extracted at time 0 and at $3 \mathrm{~h}$ of treatment.

Binding assay and analysis. Recombinant human VEGF (165 aminoacid species) produced in transfected Chinese hamster ovary cells was radiodinated as previously described (27). For binding assay, ECs were plated in either 6- or 24-well plates $\left(20000 \mathrm{cells} / \mathrm{cm}^{2}\right)$ and grown to confluence. ECs were then cultured in hypoxic or normoxic conditions or treated with hypoxia- or normoxia-CM for various lengths of time. ECs were then chilled on ice, washed twice with ice-cold PBS $+1 \%$ BSA and incubated in ice-cold binding buffer (M199 + 1\% FBS + 25 mM Hepes) containing ${ }^{125}$ I-VEGF (200 pM) for $2 \mathrm{~h}$ at $4^{\circ} \mathrm{C}$ on an orbital shaker $(40 \mathrm{rpm})$. For Scatchard analysis concentrations of ${ }^{125}$ I-VEGF between 50 and 1600 pM were used. The binding medium was then aspirated, following which ECs were washed three times with ice-cold PBS $+1 \%$ BSA, and lysed in 10 $\mathrm{mM}$ Tris, $\mathrm{pH}$ 7.4; $1 \mathrm{mM}$ EDTA; $1 \% \mathrm{NP}-40 ; 1 \mu \mathrm{M}$ leupeptin; $5 \mu \mathrm{M}$ aprotinin and $1 \mathrm{mM}$ PMSF. Lysates were counted using a Beckman Gamma 5500B counter. Triplicate samples of each condition were obtained for each experiment. Non-specific binding was determined by competition with a 200 -fold molar excess of nonradiolabeled VEGF. Specificity of binding was evaluated in preliminary experiments by addition of 100-fold molar excess of bFGF and PDGF-BB (Genzyme Corp., Cambridge, MA).

Nonlinear regression and Scatchard analysis were performed using Prism software (Graph-Pad Software, San Diego, CA). Statistical analysis was performed using ANOVA.

The number of cells $/ \mathrm{cm}^{2}$ was assessed by trypsinization and count of duplicate wells at $24 \mathrm{~h}$. Cell number were compared by $t$ test analysis.

Neutralizing antibodies. To establish the identity of putative factors responsible for the increased binding of ${ }^{125} \mathrm{I}-\mathrm{VEGF}$ to human ECs, selected neutralizing antibodies were added independently to hypoxia-CM before treatment of ECs. A rabbit polyclonal anti-tumor 
necrosis factor $\alpha$ (TNF- $\alpha$ ) antibody (Genzyme Corp.), was added at concentrations of 20 or $100 \mu \mathrm{g} / \mathrm{ml}$. A rabbit polyclonal pan-specific anti-transforming growth factor- $\beta 1$ (TGF- $\beta 1$ ) antibody (R \& D Systems, Minneapolis, MN) was used at concentrations of 30 and $100 \mu \mathrm{g} /$ $\mathrm{ml}$. A mouse monoclonal anti-bFGF antibody (UBI, Lake Placid, NY) was used at concentrations of 1 and $20 \mu \mathrm{g} / \mathrm{ml}$. In all cases binding was assessed after incubation of HUVECs for $24 \mathrm{~h}$.

To investigate the possibility that VEGF, previously shown to be upregulated in hypoxic myocytes $(12,13,17)$, could cause homologous upregulation of its receptors, VEGF $(100 \mathrm{ng} / \mathrm{ml})$ or a high concentration of neutralizing goat polyclonal anti-VEGF antibody (R \& D Systems, Minneapolis, MN) $(200 \mu \mathrm{g} / \mathrm{ml})$ were added to normoxiaand hypoxia-CM respectively, and binding assessed at $24 \mathrm{~h}$ of treatment. Finally, we tested ${ }^{125} \mathrm{I}-\mathrm{VEGF}$ binding to HUVECs treated for $24 \mathrm{~h}$ with normoxia-CM supplemented with lactic acid $(10 \mathrm{mg} / \mathrm{ml})$, a product of anaerobic glycolysis.

\section{Results}

Characterization of functional VEGF receptors in ECs. We evaluated whether active KDR and flt-1 receptors were present in HUVECs. We could detect KDR mRNA $(\sim 7 \mathrm{~kb})$ in both HUVECs and HMECs (data not shown). The phosphorylated KDR receptor was identified as a band of $\sim 210$ $\mathrm{kD}$ in immunoprecipitates of VEGF-treated, but not in control HUVECs (Fig. 1). Flt-1 mRNA ( $7.5 \mathrm{~kb})$ was detected in both HUVECs and HMECs (data not shown). However, using experimental conditions similar to those employed for KDR detection, we could not demonstrate a phosphorylated form of flt-1 receptor by immunoprecipitation of VEGF-treated HUVECs (data not shown).

Direct hypoxia does not modify ${ }^{125}$ I-VEGF binding to HUVECs. Direct hypoxic treatment of HUVECs for various lengths of time did not modify binding of ${ }^{125} \mathrm{I}-\mathrm{VEGF}$, as compared to binding to control HUVECs maintained in normoxia for the same time (Fig. 2). Similarly, exposure of HMECs to hypoxia had no detectable effect on ${ }^{125}$ I-VEGF binding (data not shown).

Effects of hypoxia on muscle cells. Because hypoxic treatment did not directly modify ${ }^{125}$ I-VEGF binding to ECs, we investigated whether hypoxic cells other than ECs could produce and/or release "factors" capable of upregulating the expression of VEGF receptors. To this purpose, we used two cell types of muscular lineage. Light microscopic examination of normoxic rat myoblasts at $4 \mathrm{~d}$ showed no evidence of dis-

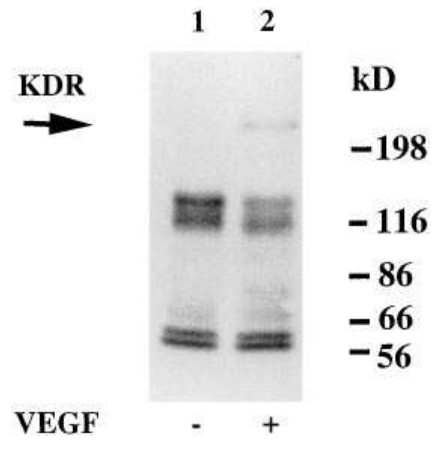

Figure 1. Detection of functional KDR receptor in ECs. HUVECs were serum-starved overnight in M199 + 1\% BSA then treated for $10 \mathrm{~min}$ with VEGF (100 ng/ml). Protein extracts $(1 \mathrm{mg} / \mathrm{sample})$ were immunoprecipitated with an antiphosphorylated tyrosine antibody, separated by $8.75 \%$ SDS-PAGE and transferred to membrane filters. Using an affinity-purified anti-KDR

rabbit polyclonal antibody, a band $(\sim 210 \mathrm{kD})$ was detected in extracts of VEGF-stimulated, but not of control HUVECs, thus indicating presence of functional KDR receptors in HUVECs. Lane 1, control HUVECs; lane 2, HUVECs treated with VEGF (100 ng/ml) for $10 \mathrm{~min}$.

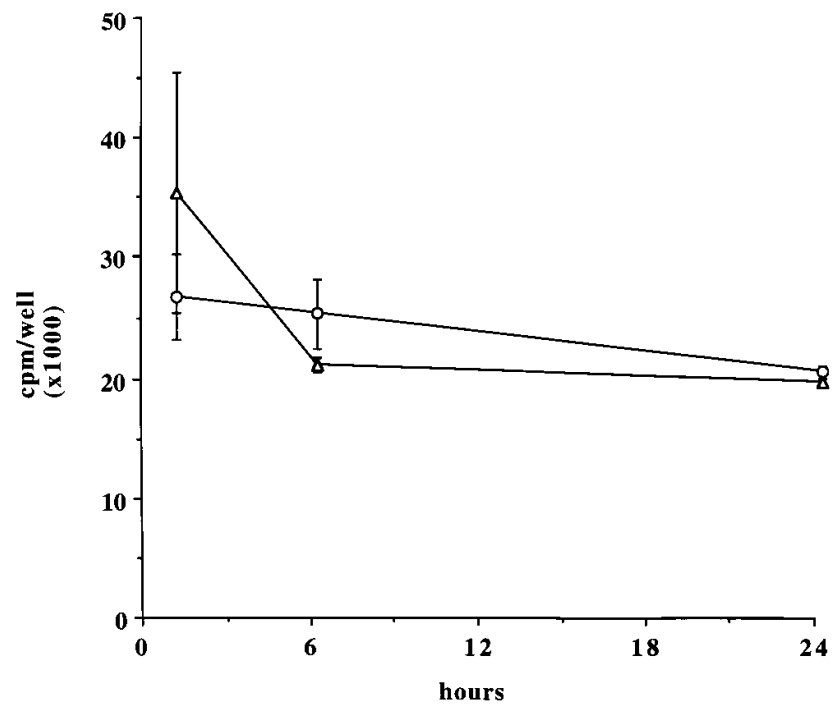

Figure 2. Exposure of ECs to hypoxia does not modify binding of ${ }^{125}$ I-VEGF. HUVECs were grown to confluence in 24-well plates, pretreated overnight with DME $+1 \%$ BSA $+1 \%$ FBS and then exposed to hypoxia for 1,6 , and $24 \mathrm{~h}$. Binding of ${ }^{125}$ I-VEGF was not modified by hypoxic treatment $(O)$ as compared to binding of

${ }^{125} \mathrm{I}-\mathrm{VEGF}$ to HUVECs maintained in normoxia $(\triangle)$. Data are presented as means $\pm \mathrm{SD}$ of triplicate samples.

tress or cell detachment; multinucleated and elongated myotubes were evident. In contrast, focal detachment of rat myoblasts was observed beginning at $48 \mathrm{~h}$ of hypoxic treatment. By day 4, detachment had extended to most of the plate surface, with only sporadic patches of cells still attached; this finding may represent the equivalent of necrosis in severely ischemic tissues.

However, $4 \mathrm{~d}$ of hypoxic treatment resulted in cellular elongation and evident network of stress fibers, but no detachment or necrosis of SMCs.

Medium conditioned by hypoxic myoblasts increases ${ }^{125}$ I-VEGF binding to human ECs. Treatment of ECs with hypoxia-CM from rat myoblasts produced a significant increase in ${ }^{125}$ I-VEGF specific binding to HUVECs (Fig. 3) and HMECs (Fig. 4). Increased binding was evident at $4 \mathrm{~h}$ of treatment, peaked at $24 \mathrm{~h}(P<.001$, for HUVECs; $P<0.003$, for HMECs) and declined slightly at $48 \mathrm{~h}$ (Fig. 3 and 4 ), although still remaining above binding levels achieved using normoxiaCM. Binding was specifically competed by addition of 200-fold molar excess of non-radiolabeled VEGF, but was not modified by addition of 100-fold molar concentrations of either bFGF or PDGF-BB (data not shown).

Scatchard analysis of HUVECs incubated with ${ }^{125}$ I-VEGF concentrated to $50 \mathrm{pM}$ or higher, indicated a single high affinity VEGF binding site. Nonlinear regression analysis of the data indicated a $K_{\mathrm{d}}=260 \pm 51 \mathrm{pM}$ in normoxia-CM and a $K_{\mathrm{d}}=$ $281 \pm 94$ in hypoxia-CM, corresponding to the reported affinity constant of $\operatorname{KDR}$ receptor $(8,28)$ (Fig. $5 A$ ). When the number of receptors/cell was calculated from Bmax values $(10 \mathrm{pM}$, normoxia-CM versus $40 \mathrm{pM}$, hypoxia-CM), a 13-fold increase in KDR receptors present on the surface of HUVECs after treatment with hypoxia-CM was detected (normoxia-CM, $1.7 \times 10^{3}$ receptors/cell; hypoxia-CM $23 \times 10^{3}$ receptors/cell) (Fig. $5 B$ ). 


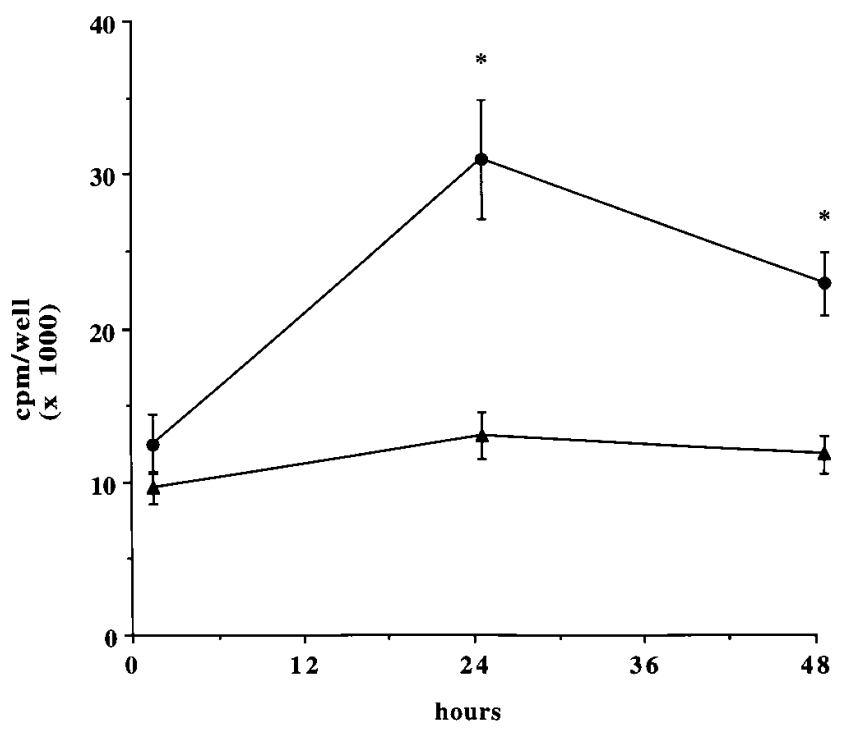

Figure 3. Hypoxia-conditioned medium increases ${ }^{125}$ I-VEGF binding to HUVECs. Confluent HUVECs in 24-well plates were pretreated overnight with DME + 1\% BSA + 1\% FBS, then with CM from hypoxic or normoxic rat myoblasts. Binding of ${ }^{125} \mathrm{I}-\mathrm{VEGF}$ was assessed at 1, 24, and 48 h. ${ }^{125}$ I-VEGF specific binding increased by threefold after treatment with $\mathrm{CM}$ by hypoxic rat myoblasts $(\mathbf{)})$ versus treatment with $\mathrm{CM}$ by normoxic cells $(\boldsymbol{\Delta})$. Binding peaked at $24 \mathrm{~h}$, and was still elevated at $48 \mathrm{~h}\left({ }^{*} P<0.001\right.$, ANOVA $)$. Data are presented as means $\pm \mathrm{SD}$ of triplicate samples.

The difference in binding was not due to a difference in cell number, as HUVECs at $24 \mathrm{~h}$ totaled $33.5 \pm 5.5 \times 10^{3} \mathrm{ECs} / \mathrm{cm}^{2}$ when maintained in hypoxia-CM versus $35.6 \pm 5.9 \times 10^{3} \mathrm{ECs} /$ $\mathrm{cm}^{2}$ when maintained in normoxia-CM (unpaired Student's $t$ test $=$ NS).

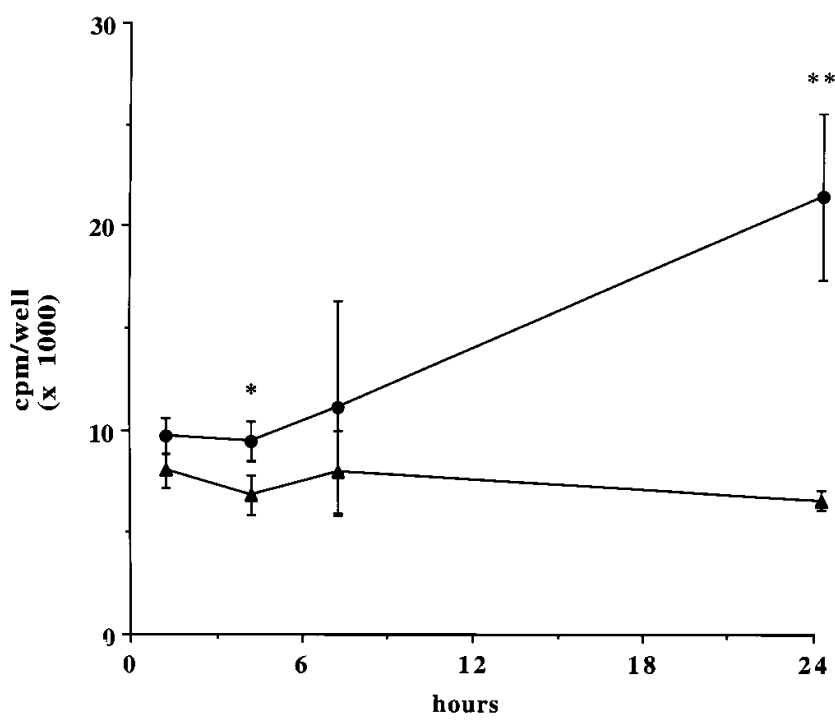

Figure 4. Hypoxia-conditioned medium increases ${ }^{125}$ I-VEGF binding to HMECs. Confluent HMECs in 24-well plates were pretreated overnight with DME $+1 \%$ BSA $+1 \%$ FBS, then treated for $1,4,7$, and $24 \mathrm{~h}$ with $\mathrm{CM}$ by hypoxic or normoxic rat myoblasts. ${ }^{125}$ I-VEGF specific binding to HMECs increased by threefold after treatment with hypoxia-CM $(\bullet)$, as compared to treatment with normoxia-CM $(\Delta)$. Binding increased progressively and peaked at $24 \mathrm{~h} .{ }^{*} P<0.02$; $* * P<0.003$; ANOVA). Data are presented as means \pm SD of triplicate samples.
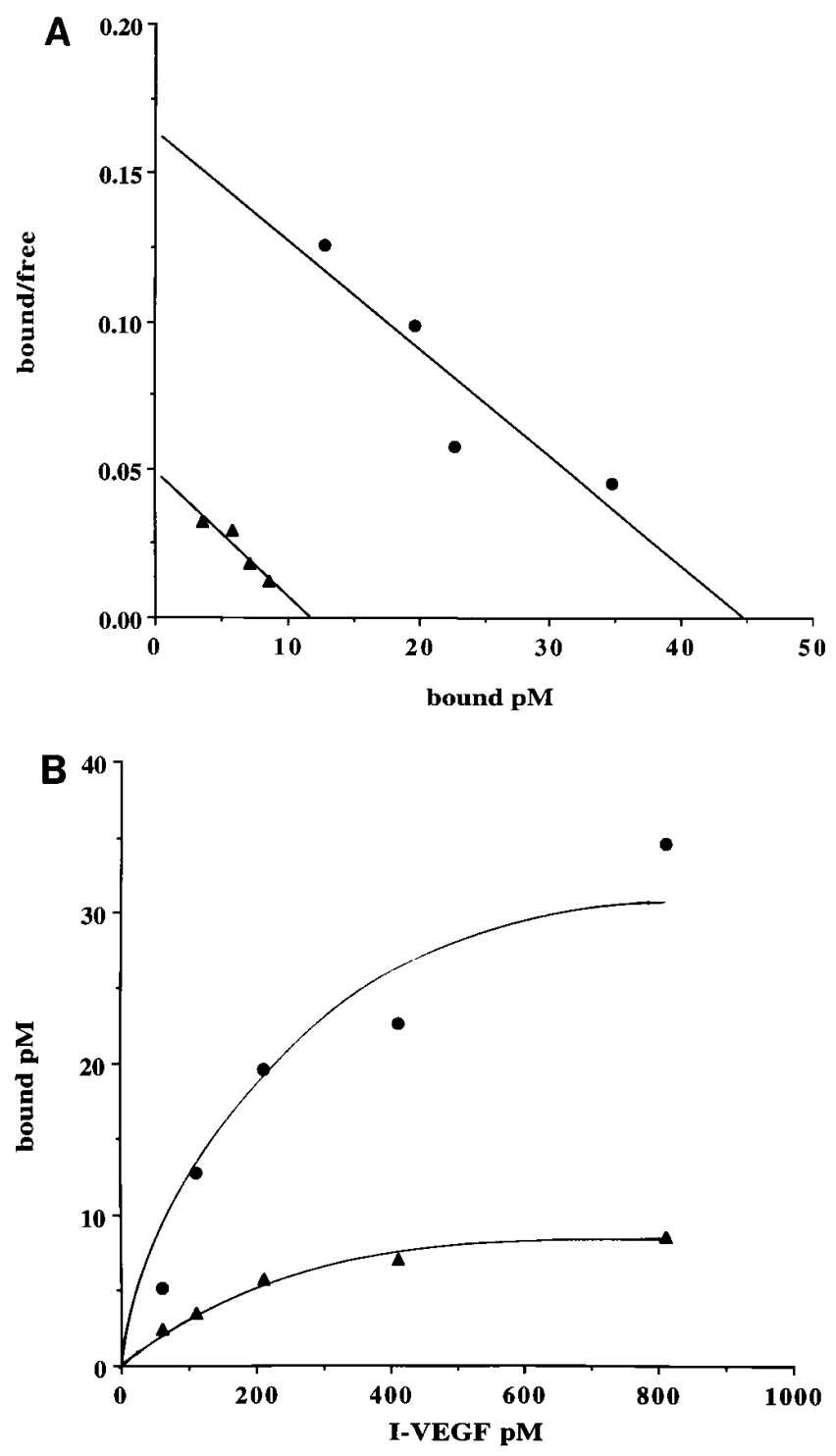

Figure 5. Treatment of ECs with hypoxia-conditioned medium increases the number of KDR receptors. ( $A$ ) Scatchard analysis of ${ }^{125}$ I-VEGF specific binding to HUVECs treated with hypoxia- or normoxia-CM for $24 \mathrm{~h}$. When concentrations of ${ }^{125}$ I-VEGF $\geq 50 \mathrm{pM}$ were used, binding was predominantly due to one receptor species $\left(K_{\mathrm{d}}=260 \pm 51 \mathrm{pM}\right.$ in normoxia-CM versus $K_{\mathrm{d}}=281 \pm 94 \mathrm{pM}$ in hypoxia-CM). The number of receptors increased 13-fold in ECs treated with hypoxia-CM $(\bullet)$, as compared with treatment with normoxia-CM $(\boldsymbol{\Delta})$. (B) Specific binding of ${ }^{125}$ I-VEGF to HUVECs treated for $24 \mathrm{~h}$ in normoxia- $(\mathbf{\Delta})$ or hypoxia- $(\mathbf{O}) \mathrm{CM}$ from rat myoblasts.

Dilution of hypoxia-CM with normoxia-CM blunted the increase in ${ }^{125} \mathrm{I}-\mathrm{VEGF}$ binding to HUVECs. When normoxia$\mathrm{CM}$ was used to dilute hypoxia-CM by $50 \%$, bound ${ }^{125}$ I-VEGF (cpm/well) decreased by 50\%; binding to ECs treated with 1:4 or greater dilution of hypoxia-CM equalized levels of binding obtained with normoxia-CM (data not shown). Heat inactivation of CM resulted in similar levels of ${ }^{125}$ I-VEGF binding by hypoxia-CM and normoxia-CM treated HUVECs (data not shown). The $\mathrm{pH}$ of normoxia- and hypoxia-CM did not remarkably differ ( $\mathrm{pH} 7.6$ versus $\mathrm{pH} 7.5$, respectively), probably due to the presence of Hepes buffer in the media. Therefore, the observed difference in ${ }^{125} \mathrm{I}-\mathrm{VEGF}$ binding was not due to 
difference in $\mathrm{pH}$ of CM. Finally, as expected, lactic acid levels were remarkably different $(0.6 \mathrm{mg} / \mathrm{ml}$ in normoxia-CM versus $9.5 \mathrm{mg} / \mathrm{ml}$ in hypoxia-CM). However, treatment of HUVECs with normoxia-CM supplemented with lactic acid $(10 \mathrm{mg} / \mathrm{ml})$ did not modify ${ }^{125}$ I-VEGF binding to HUVECs (data not shown). These data exclude that increased binding of ${ }^{125}$ I-VEGF to ECs treated with hypoxia-CM was due to variation in $\mathrm{pH}$ or lactic acid content of the medium.

Medium conditioned by hypoxic smooth muscle cells increases ${ }^{125} I$-VEGF binding to human HUVECs. To evaluate whether only hypoxia-CM from transformed cells (rat myoblasts) could increase binding of VEGF to ECs, binding experiments were performed after treatment of HUVECs with hypoxia-CM obtained from non-transformed SMCs. Similar to the results obtained with rat myoblast $\mathrm{CM}$, medium conditioned for $4 \mathrm{~d}$ by hypoxic SMCs induced a 1.7 -fold increase in ${ }^{125}$ I-VEGF binding to HUVECs (data not shown).

Medium conditioned by hypoxic myoblasts increases $K D R$ $m R N A$ levels in HUVECs. Levels of KDR mRNA (main band of $\sim 7 \mathrm{~kb}$ ) were very low in HUVECs starved overnight in DMEM $+1 \%$ BSA $+1 \%$ FBS. Treatment of HUVECs with hypoxia-CM for $3 \mathrm{~h}$ increased KDR mRNA species, compared with baseline levels and with corresponding mRNA species in HUVECs treated for $3 \mathrm{~h}$ with normoxia-CM (Fig. 6).

Addition of neutralizing antibodies to hypoxia conditioned medium does not attenuate ${ }^{125}$ I-VEGF binding. To investigate whether known factors, likely to be produced and/or released by hypoxic myoblasts, could be responsible for the increased binding of ${ }^{125}$ I-VEGF to ECs treated with hypoxia-CM, antibodies capable of neutralizing candidate growth factors bFGF, TGF- $\beta 1$ or TNF- $\alpha$ were added to the hypoxia-CM. bFGF is released by cells following cell damage and/or injury (29). TGF-
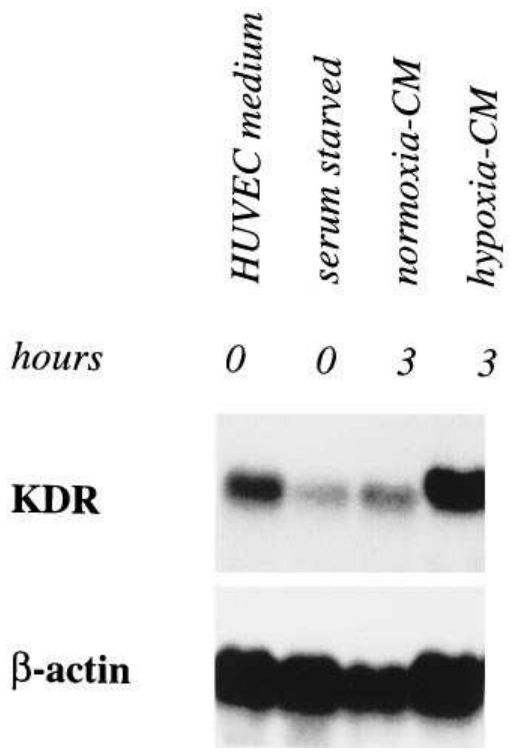

Figure 6. Treatment of ECs with hypoxia-conditioned medium increases KDR mRNA levels. Northern analysis of KDR mRNA levels in HUVECs. Cells were maintained in HUVEC complete culture medium, serum starved overnight in DME $+1 \%$ BSA $+1 \%$ FBS (time 0 ), followed by treatment for $3 \mathrm{~h}$ with normoxia- or hypoxia-CM. Treatment with hypoxia-CM increased KDR mRNA levels. Levels of $\beta$-actin mRNA are shown for comparison of RNA loading in each lane. $\beta 1$ modulates epidermal growth factor receptor expression (30). TNF- $\alpha$ is produced by certain cell types in response to hypoxia (31). However, neutralization of bFGF, TGF- $\beta 1$ and TNF- $\alpha$ did not affect ${ }^{125}$ I-VEGF binding to ECs (Fig. 7).

Increased ${ }^{125}$ I-VEGF binding is not due to homologous regulation by VEGF. VEGF is produced by human SMCs (17) and by myoblasts (13) in response to hypoxia. Therefore, VEGF present in hypoxia-CM could potentially cause upregulation of its own receptors. However, the addition of recombinant VEGF to the normoxia-CM did not affect ${ }^{125} \mathrm{I}-\mathrm{VEGF}$ binding (Fig. 7). Furthermore, addition of high dose of antiVEGF neutralizing antibody to hypoxia-CM actually increased ${ }^{125}$ I-VEGF binding to HUVECs (Fig. 8).

These results confirm that hypoxia-CM contains VEGF. However, under the conditions tested, VEGF does not induce upregulation of its own receptors.

\section{Discussion}

VEGF is regarded as a fundamental mediator of hypoxiainduced angiogenesis. In vitro, the expression of this growth factor increases specifically in cells exposed to hypoxia (13, 17). In vivo, increased VEGF expression occurs in a variety of pathological processes characterized by hypoxia-related neovascularization. For example, VEGF production is augmented during wound healing (9), as low oxygen tension occurs in the central part of a wound after disruption of local vasculature (22). VEGF levels are increased during revascularization of ischemic, and therefore hypoxic, hearts (11). In a recent report, increased VEGF expression has been detected in lungs of rats exposed to acute or chronic hypoxia (32). In addition, even in tumors, the production of VEGF appears not uniquely determined by the genetic program of neoplastic cells $(14,15,33)$, but it is still inducible by hypoxic stimulation $(20)$.

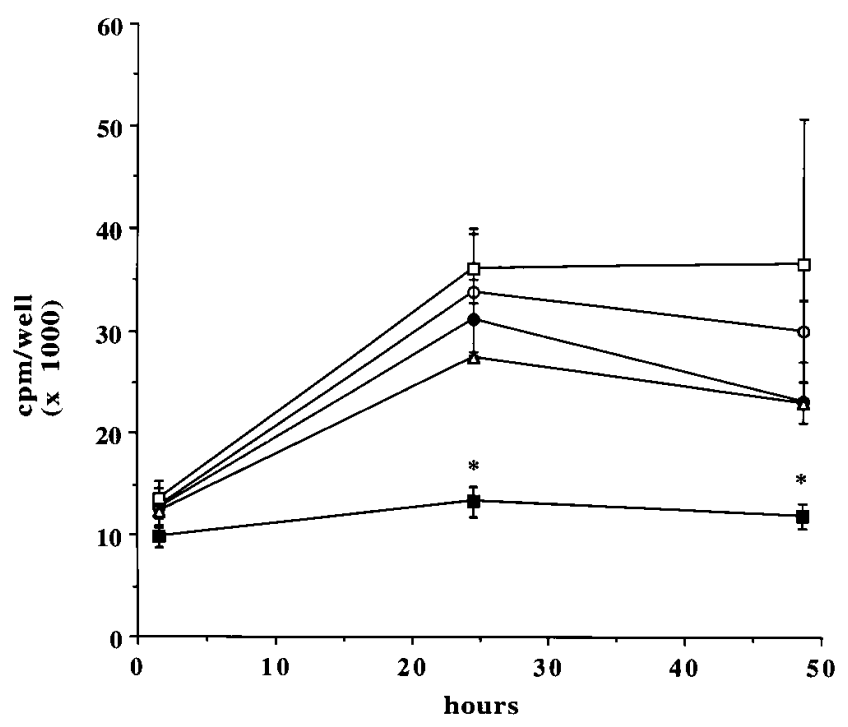

Figure 7. Increased binding of ${ }^{125} \mathrm{I}-\mathrm{VEGF}$ to ECs treated with hypoxia-conditioned medium is not due to TNF- $\alpha$, TGF- $\beta 1$ or bFGF. Addition of high-dose neutralizing antibodies anti-TNF- $\alpha(100 \mu \mathrm{g} /$ $\mathrm{ml})(\square)$, anti-TGF- $\beta 1(100 \mu \mathrm{g} / \mathrm{ml})(\bigcirc)$ and anti-bFGF $(20 \mu \mathrm{g} / \mathrm{ml})(\triangle)$ to hypoxia-CM does not modify ${ }^{125}$ I-VEGF specific binding to

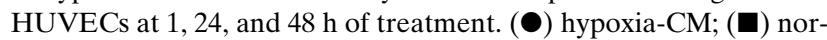
moxia-CM. Data are presented as means \pm SD of triplicate samples. 


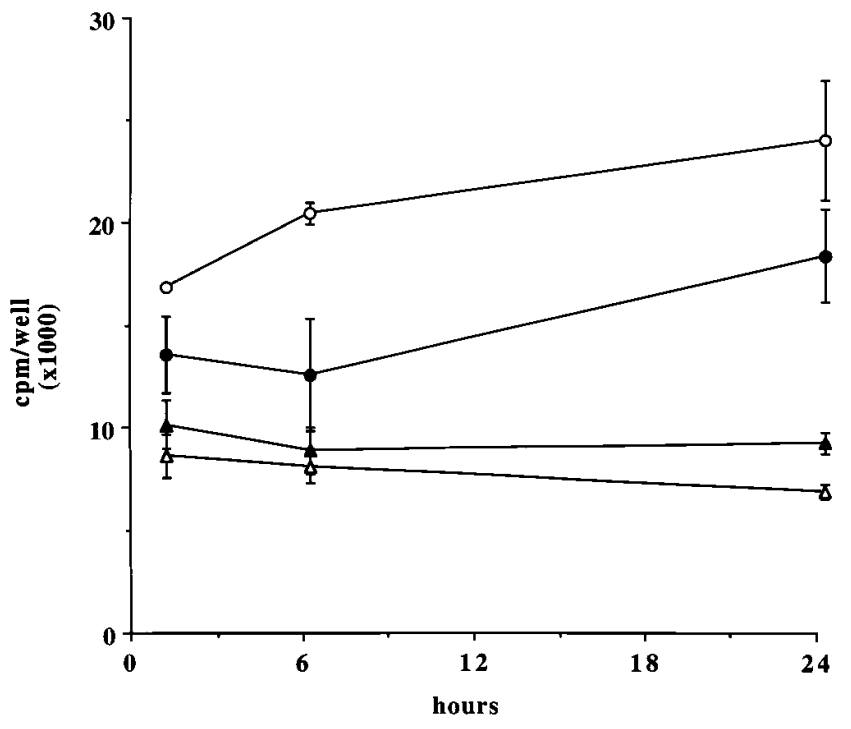

Figure 8. VEGF/VPF does not upregulate the expression of KDR receptors in ECs. Addition of neutralizing anti-VEGF $(200 \mu \mathrm{g} / \mathrm{ml})$ antibody to hypoxia-CM $(O)$ further increases ${ }^{125}$ I-VEGF binding to HUVECs at 1, 6, and $24 \mathrm{~h}$ of treatment. Addition of VEGF (100 ng/ $\mathrm{ml})$ to normoxia-CM $(\triangle)$ has no remarkable effect on ${ }^{125}$ I-VEGF binding. (๑) hypoxia-CM; $(\mathbf{\square})$ normoxia-CM. Data are presented as means \pm SD of triplicate samples.

Two specific VEGF receptors, located on ECs, have been identified to date. They are KDR (6) and flt-1 (7), both tyrosine-kinases that autophosphorylate in response to VEGF treatment. Data from our laboratory using a rabbit ischemic hindlimb model indicated that systemic administration of VEGF protein selectively produces neovascularization in the ischemic limb (23); neither in the contralateral normal limb nor in any other organs were foci of neovascularization observed. Thus, in this experimental model, exogenously administered VEGF appears to be biologically "sequestered" and its activity limited uniquely to ischemic regions, perhaps due to local upregulation of its receptors. In vivo, increased expression of endogenous VEGF has been extensively documented in many pathologic tissues $(9,11,13-15,20,32,34,35)$. Moreover, increased expression of VEGF receptor mRNA species strictly limited to ECs of the same pathologic tissues $(14,15$, $32,34,35)$ has been reported as well. These data suggest that hypoxia could affect angiogenesis $(13,14,17,22)$ not only by inducing the expression of $\operatorname{VEGF}(13,14,17)$, a specific angiogenic growth factor, but also by causing a coordinated increase of the expression of VEGF/VPF receptors. However, whether the upregulation of VEGF receptors observed in vivo is promoted directly by hypoxia or secondarily, by local events induced by hypoxia remains to be determined. Accordingly, we investigated the possibility that hypoxia or hypoxia-dependent conditions could affect the specific binding of ${ }^{125}$ I-VEGF to ECs. These experiments were performed on ECs in vitro, as hypoxic conditions are difficult to document and reproduce in vivo. Furthermore, we used human ECs obtained from two different vascular districts, as intrinsic differences exist among ECs from various vascular beds (36).

We first evaluated binding of ${ }^{125}$ I-VEGF to HUVECs and HMECs after exposure to low oxygen tension for various lengths of time, from 1 to $48 \mathrm{~h}$. Although we cannot exclude with certainty that direct exposure of ECs to hypoxia might affect binding of ${ }^{125} \mathrm{I}-\mathrm{VEGF}$ to ECs in vivo, our results indicate that low oxygen tension does not modulate such an event in vitro.

In a recent report, Thieme et al. reported that hypoxic stimulation of bovine retinal ECs induced a $50 \%$ increase in the level of VEGF receptors in this cell type (37). The direct effect of hypoxia on VEGF receptors in bovine retinal ECs could reflect intrinsic differences between ECs from different vascular districts (36). In particular, under basal conditions bovine retinal ECs possess three-fold more VEGF receptors than bovine aortic ECs (37). We had no opportunity to test ${ }^{125}$ I-VEGF binding to retinal ECs, but we consistently obtained no detectable effect of hypoxia on ${ }^{125}$ I-VEGF binding to the EC types tested.

To further evaluate the possibility of upregulation of VEGF receptors in response to conditions of low oxygen tension, we hypothesized that hypoxia might "indirectly" effect ECs. According to this hypothesis, "factor (s)" produced and/ or released by hypoxic cells different from ECs might regulate the expression of VEGF receptors on ECs. To test this hypothesis we initially assessed the binding of ${ }^{125}$ I-VEGF to ECs treated with medium conditioned by L6 rat myoblasts maintained in hypoxia for 4 days.

We chose to use rat myoblast $\mathrm{CM}$ for various reasons. First, our observation of site-specific angiogenesis after systemic administration of VEGF was obtained using an experimental model of hindlimb ischemia (23). This model is characterized by profound reduction of blood perfusion of the ischemic limb, with consequent hypoxia of muscular tissues. L6 rat myoblasts, transformed cells of muscular lineage, can be used to generate adequate volumes of CM. The treatment of ECs with medium conditioned by rat myoblasts in hypoxia for $4 \mathrm{~d}$, caused a threefold increase of ${ }^{125} \mathrm{I}-\mathrm{VEGF}$ specific binding. Such increase was consistently obtained when either HUVECs or HMECs were tested, and was maximal after $24 \mathrm{~h}$ of stimulation.

Because L6 rat myoblasts are a transformed cell line, we also tested CM obtained from non-transformed SMCs. These cells were isolated and grown from apparently healthy internal mammary arteries obtained at coronary artery bypass surgery. Microscopic examination of segments from similarly obtained arteries showed no apparent sign of abnormality. SMCs exposed to hypoxia for $4 \mathrm{~d}$ were intact and showed no signs of necrosis. Medium conditioned by hypoxic SMCs induced a significant increase of ${ }^{125}$ I-VEGF binding to HUVECs. Therefore, we conclude that products released by cells undergoing necrosis as a consequence of severe hypoxia are not necessary for induction of VEGF receptor upregulation in ECs treated with hypoxia-CM. Furthermore, these data suggest the existence of a regulatory mechanism, common to transformed and non-transformed cells, which might coordinate angiogenesis under hypoxic conditions.

We could not detect a functional flt-1 receptor in HUVECs. Bikfalvi et al. reported that number of flt-1 receptors in HUVECs is approximately ten-fold lower than that of KDR receptors (28). In addition, Waltenberger et al. have demonstrated that VEGF stimulation of transfected cells overexpressing flt-1 does not induce any known biological effects attributed to VEGF (8). These observations led the authors to question the functional role of this high affinity VEGF receptor (8). The reported $K_{\mathrm{d}}$ of flt-1 ranges between 9 and $16 \mathrm{pM}$ $(8,28)$. Preliminary experiments indicated that when ${ }^{125} \mathrm{I}-\mathrm{VEGF}$ 
was concentrated to $50 \mathrm{pM}$ or higher, we could regard the contribution of the flt- 1 receptor to ${ }^{125} \mathrm{I}-\mathrm{VEGF}$ binding as negligible. We therefore assessed binding at concentrations of ${ }^{125} \mathrm{I}-\mathrm{VEGF} \geq 50 \mathrm{pM}$, as flt- 1 receptors appeared to be saturated at these concentrations.

We identified a functional KDR receptor in HUVECs. Moreover, the $K_{\mathrm{d}}$ of the high affinity receptor species detected using ${ }^{125}$ I-VEGF concentrated to $50 \mathrm{pM}$ or higher conformed to $K_{\mathrm{d}}$ values of KDR receptor previously reported by others $(8,28)$. Furthermore, an increase of KDR mRNA levels was detected in HUVECs treated for $3 \mathrm{~h}$ with hypoxia-CM, as compared to KDR mRNA levels of HUVECs treated for the same time with normoxia-CM. Such an increase suggests that new synthesis of the receptor might be occurring, in conjunction with mobilization of preformed receptors from the cellular pool.

Under the conditions tested, Scatchard analysis of ${ }^{125}$ I-VEGF binding indicated no substantial change in affinity of the KDR receptor in HUVECs treated with rat myoblasts medium conditioned either in normoxia or hypoxia. Thus, increased binding observed using hypoxia-CM was due to a 13fold increase in the number of KDR receptors. Heldin and coworkers (8) have recently demonstrated that VEGF-induced effects on ECs in vitro are mediated via KDR receptors. Moreover, Park et al. have reported that placenta growth factor (PIGF), a member of the VEGF family of growth factors, binds to flt-1, but not to KDR receptors (38). Treatment of ECs with PlGF elicited no mitogenic or permeability-enhancing activity. However, PlGF was able to potentiate the biological effects of low doses of VEGF both in vitro and in vivo, probably by displacing VEGF bound to flt-1, and therefore increasing VEGF availability to the more relevant $f l k-1 / \mathrm{KDR}$ receptors (38). Studies conducted in vivo using a dominantnegative mutant of $f l k-1$, the mouse homologue of KDR receptor, also have emphasized the fundamental role of $f l k-1 / \mathrm{KDR}$ in VEGF induced angiogenesis (39). Finally, $f l k-1 / \mathrm{KDR}$ temporally and spatially correlates with VEGF expression during development, suggesting a major role of this ligand-receptor system in vasculogenesis and angiogenesis (40). These data strongly suggest a relevant role of KDR in mediating VEGF biological effects. We found that increased binding of ${ }^{125}$ I-VEGF to HUVECs in response to indirect hypoxia is mainly due to KDR. Mobilization of KDR receptors from the cellular pool, suggested by the rapid increase in ${ }^{125} \mathrm{I}-\mathrm{VEGF}$ binding, as well as new synthesis following upregulation of KDR mRNA, may contribute to the global increase of KDR receptors expressed on the surface of ECs treated with hypoxia-CM.

The particular component of hypoxia-CM responsible for increased binding of ${ }^{125} \mathrm{I}$-VEGF to ECs remains to be identified. Treatment of HUVECs with hypoxia-CM diluted with normoxia-CM caused diminished binding compared to treatment with undiluted hypoxia-CM; hypoxia-CM diluted to $25 \%$ with normoxia-CM produced no appreciable difference in binding compared to normoxia-CM alone. bFGF potently synergizes with VEGF in inducing angiogenesis in vitro $(41,42)$. Such synergism could be due to an upregulation of VEGF receptor number by bFGF. Although bFGF expression is not induced by hypoxia (17), this growth factor can be released as a consequence of cell damage (29) or mobilization from deposits in the extracellular matrix (43). TNF- $\alpha$ is an indirect angiogenic growth factor (44), specifically induced by hypoxic stim- ulation (22). TGF- $\beta 1$, an indirect growth factor itself, can also modulate the number of epidermal growth factor receptors on certain cell types (30). Therefore we tried to specifically neutralize these candidate growth factors possibly present in the hypoxia-CM. In no case, however, did the addition of neutralizing antibodies diminish the increase in ${ }^{125} \mathrm{I}-\mathrm{VEGF}$ binding due to hypoxia-CM.

Finally, hypoxic treatment of muscle cells induces expression of VEGF itself $(13,17)$. As homologous upregulation of receptors by their specific ligands has been previously described for certain growth factors (45), we investigated the possibility that VEGF present in hypoxia-CM could upregulate its own receptors. Again, the addition of VEGF to normoxia-CM did not modify ${ }^{125} \mathrm{I}-\mathrm{VEGF}$ binding. Moreover, the addition of an anti-VEGF neutralizing antibody to hypoxia$\mathrm{CM}$ further increased the ${ }^{125} \mathrm{I}-\mathrm{VEGF}$ binding to ECs. These data therefore exclude the possibility of homologous upregulation of the receptors by VEGF itself.

These data suggest that a "factor" present in hypoxia-CM might be important in modulating VEGF specific binding to ECs. Further experiments will establish whether hypoxic cells (a) release a "factor capable of increasing the expression of VEGF receptors; $(b)$ down-regulate an inhibitor of VEGF receptor expression normally produced by cells; or (c) release a "factor" capable of blocking a putative VEGF receptor inhibitor normally produced by cells.

Our results suggest that paracrine mechanisms initiated by hypoxia can operate to induce angiogenesis in ischemic tissues. Hypoxic cells different from ECs can both produce VEGF, as previously demonstrated by us and others, and also produce soluble factors capable of upregulating the expression of $\mathrm{KDR}$, a functional VEGF/VPF receptor, on ECs. It is intriguing that this paracrine mechanism may operate in vivo not only in hypoxic areas of tumors but also in nonneoplastic conditions, such as in ischemic peripheral vascular disease.

\section{Acknowledgments}

We thank Napoleone Ferrara, Genentech Inc., for providing us with human VEGF cDNA; Lewis T. Williams, UCSF, for providing us with a human flt-1 DNA probe; Bruce Terman, American Cyanamid, for providing us with a human KDR DNA probe and with the affinity purified rabbit polyclonal anti-KDR antibody; and Mrs. Mickey Neely for expert secretarial assistance.

This work was supported in part by grants HL-40518, HL-53354, HL-02824 (to J. M. Isner) and CA53094 (to L. Varticovski) from the National Institutes of Health; and a Grant-in-Aid (to G. Schatteman) from the Massachusetts Affiliate of the American Heart Association.

\section{References}

1. Leung, D., G. Cachianes, W. Kuang, D. Goeddel, and N. Ferrara. 1989. Vascular endothelial growth factor is a secreted angiogenic mitogen. Science (Wash. DC). 246:1306-1312.

2. Senger, D. R., S. J. Galli, A. M. Dvorak, C. A. Perruzzi, V. S. Harvey, and H. F. Dvorak. 1983. Tumor cells secrete a vascular permeability factor that promotes accumulation of ascites fluid. Science (Wash. DC). 219:983-985.

3. Connolly, D. T., D. M. Heuvelman, R. Nelson, J. V. Olander, B. L. Eppley, J. J. Delfino, N. R. Siegel, R. M. Leimgruber, and J. Feder. 1989. Tumor vascular permeability factor stimulates endothelial cell growth and angiogenesis. J. Clin. Invest. 84:1470-1478.

4. Takeshita, S., L. P. Zheng, E. Brogi, M. Kearney, L. Q. Pu, S. Bunting, N. Ferrara, J. F. Symes, and J. M. Isner. 1994. Therapeutic angiogenesis: a single intra-arterial of bolus of vascular endothelial growth factor augments revascularization in a rabbit ischemic hindlimb model. J. Clin. Invest. 93:662-670.

5. Ferrara, N., K. A. Houch, L. B. Jakeman, and D. W. Leung. 1992. Molec- 
ular and biological properties of the vascular endothelial growth factor family of protein. Endocrin. Rev. 13:18-32.

6. Terman, B. I., M. Dougher-Vermazen, M. E. Carrion, D. Dimitrov, D. C. Armellino, D. Gospodarowicz, and P. Bohlen. 1992. Identification of the KDR tyrosine kinase as a receptor for vascular endothelial growth factor. Biochem. Biophys. Res. Commun. 187:1579-1586.

7. de Vries, C., J. A. Escobedo, H. Ueno, K. Houck, N. Ferrara, and L. T. Williams. 1990. The fms-like tyrosine kinase, a receptor for vascular endothelial growth factor. Science (Wash. DC). 87:2628-2632.

8. Waltenberger, J., L. Claesson-Welsh, A. Siegbahn, M. Shibuya, and C. H. Heldin. 1994. Different signal transduction properties of KDR and flt-1, two receptors for vascular endothelial growth factor. J. Biol. Chem. 269:26988-26995.

9. Brown, L. F., K. T. Yeo, B. Berse, T. K. Yeo, D. R. Senger, H. F. Dvorak, and L. Van de Water. 1992. Expression of vascular permeability factor (vascular endothelial growth factor) by epidermal keratinocytes during wound healing. J. Exp. Med. 176:1375-1379.

10. Pierce, E. A., R. L. Avery, E. D. Foley, L. P. Aiello, and L. E. H. Smith. 1995. Vascular endothelial growth factor/vascular permeability factor expression in a mouse model of retinal neovascularization. Proc. Natl. Acad. Sci. USA. 92:905-909.

11. Hashimoto, E., T. Ogita, T. Nakaoka, R. Matsuoka, A. Takao, and Y. Kira. 1994. Rapid induction of vascular endothelial growth factor by transient ischemia in rat heart. Am. J. Physiol. Heart Circ. Physiol. 267:H1948-H1954.

12. Banai, S., D. Shweiki, A. Pinson, M. Chandra, G. Lazarovici, and E. Keshet. 1994. Upregulation of vascular endothelial growth factor expression induced by myocardial ischaemia: implications for coronary angiogenesis. Cardiovasc. Res. 28:1176-1179.

13. Shweiki, D., A. Itin, D. Soffer, and E. Keshet. 1992. Vascular endothelial growth factor induced by hypoxia may mediate hypoxia-initiated angiogenesis. Science (Wash. DC). 359:843-845.

14. Plate, K. H., G. Breier, H. A. Weich, and W. Risau. 1992. Vascular endothelial growth factor is a potential tumor angiogenesis factor in human gliomas in vivo. Nature (Lond.). 359:845-848.

15. Brown, L. F., B. Berse, R. W. Jackman, K. Tognazzi, A. J. Guidi, H. F. Dvorak, D. R. Senger, J. L. Connolly, and S. J. Schnitt. 1995. Expression of vascular permeability factor (vascular endothelial growth factor) and its receptors in breast cancer. Hum. Pathol. 26:86-91.

16. Hatva, E., A. Kaipainen, P. Mentula, J. Jaaskelainen, A. Paetau, M. Haltia, and K. Alitalo. 1995. Expression of endothelial cell-specific receptor tyrosine kinases and growth factors in human brain tumors. Am. J. Pathol. 146: 368-378

17. Brogi, E., T. Wu, A. Namiki, and J. M. Isner. 1994. Indirect angiogenic cytokines upregulate VEGF and bFGF gene expression in vascular smooth muscle cells, whereas hypoxia upregulates VEGF expression only. Circulation. 90:649-652.

18. Iizuki, M., M. Yamauchi, K. Ando, N. Hori, Y. Furusawa, H. Itsukaichi, K. Fukutsu, and H. Morya. 1994. Quantitative RT-PCR assay detecting the transcriptional induction of vascular endothelial growth factor under hypoxia. Biochem. Biophys. Res. Commun. 205:1474-1480.

19. Boucher, Y., and R. K. Jain. 1992. Microvascular pressure is the principal driving force for interstitial hypertension in solid tumors: implications for vascular collapse. Cancer Res. 52:5110-5114.

20. Shweiki, D., M. Neeman, A. Itin, and E. Keshet. 1995. Induction of vascular endothelial growth factor expression by hypoxia and by glucose deficiency in multicell spheroids: implications for tumor angiogenesis. Proc. Natl. Acad. Sci. USA. 92:768-772.

21. Peters, K. G., C. DeVries, and L. T. Williams. 1993. Vascular endothelial growth factor receptor expression during embryogenesis and tissue repair suggests a role in endothelial differentiation and blood vessel growth. Proc. Natl. Acad. Sci. USA. 90:8915-8919.

22. Knighton, D. R., T. K. Hunt, H. Scheuenstuhl, B. J. Halliday, Z. Werb, and M. J. Banda. 1983. Oxygen tension regulates the expression of angiogenesis factor by macrophages. Science (Wash. DC). 221:1283-1285

23. Bauters, C., T. Asahara, L. Zheng, S. Takeshita, S. Bunting, N. Ferrara, J. F. Symes, and J. M. Isner. 1995. Site-specific therapeutic angiogenesis following systemic administration of vascular endothelial growth factor. J. Vasc. Surg. 21:314-325.

24. Jaffe, E. A., R. L. Nachman, C. G. Becker, and C. R. Minick. 1973. Culture of human endothelial cells derived from umbilical veins. J. Clin. Invest. 52: 2745-2756.

25. Pickering, J. G., L. Weir, K. Rosenfield, J. Stetz, J. Jekanowski, and
J. M. Isner. 1992. Smooth muscle cell outgrowth from human atherosclerotic plaque: implications for the assessment of lesion biology. J. Am. Coll. Cardiol. 20:1430-1439.

26. Whitman, M., D. R. Kaplan, B. Schaffhausen, L. Cantley, and T. M. Roberts. 1985. Association of phosphatidylinositol kinase activity with polyoma middle-T competent for transformation. Nature (Lond.). 315:239-242.

27. Jakeman, L. B., J. Winer, G. L. Bennett, C. A. Altar, and N. Ferrara. 1992. Binding sites for vascular endothelial growth factor are localized on endothelial cells in adult rat tissues. J. Clin. Invest. 89:244-253.

28. Bikfalvi, A., C. Sauzeau, H. Moukadiri, J. Maclouf, N. Busso, M. Bryckaert, J. Plouet, and G. Tobelem. 1991. Interaction of vasculotropin/vascular endothelial cell growth factor with human umbilical vein endothelial cell: binding, internalization, degradation, and biological effects. J. Cell. Physiol. 149:50-59.

29. Muthukrishnan, L., E. Warder, and P. L. McNeil. 1991. Basic fibroblast growth factor is efficiently released from a cytosolic storage site through plasma membrane disruptions of endothelial cells. J. Cell. Physiol. 148:1-16.

30. Assoian, R. K. 1994. Biphasic effects of type $\beta$ transforming growth factor on epidermal growth factor receptors in NRK fibroblasts. J. Biol. Chem. 260:9613-9617.

31. Ghezzi, P., C. A. Dinarello, M. Bianchi, M. E. Rosandich, J. E. Repine, and C. W. White. 1991. Hypoxia increases production of interleukin-1 and tumor necrosis factor by human mononuclear cells. Cytokine. 3:189-194.

32. Tuder, R. M., B. E. Flook, and N. F. Voelkel. 1995. Increased gene expression of VEGF and the VEGF receptors KDR/Flk and Flt in lungs exposed to acute or chronic hypoxia. J. Clin. Invest. 95:1798-1807.

33. Wizigmann-Voos, S., G. Breier, W. Risau, and K. H. Plate. 1995. Upregulation of vascular endothelial growth factor and its receptors in von HippelLindau disease-associated and sporadic hemangioblastomas. Cancer Res. 55: 1358-1364.

34. Plate, K. H., G. Breier, H. A. Weich, H. D. Mennel, and W. Risau. 1994. Vascular endothelial growth factor and glioma angiogenesis: coordinate induction of VEGF receptors, distribution of VEGF protein and possible in vivo regulatory mechanisms. Int. J. Cancer 59:520-529.

35. Warren, R. S., H. Yuan, M. R. Matli, N. A. Gillett, and N. Ferrara. 1995. Regulation by vascular endothelial growth factor of human colon cancer tumorigenesis in a mouse model of experimental liver metastasis. J. Clin. Invest. 95: 1789-1797.

36. Page, C., M. Rose, M. Yacoub, and R. Pigott. 1992. Antigenic heterogeneity of vascular endothelium. Am. J. Pathol. 141:673-683.

37. Thieme, H., L. P. Aiello, H. Takagi, N. Ferrara, and G. L. King. 1995. Comparative analysis of vascular endothelial growth factor receptors on retinal and aortic vascular endothelial cells. Diabetes. 44:98-103.

38. Park, J. E., H. H. Chen, J. Winer, K. A. Houck, and N. Ferrara. 1994 Placenta growth factor. Potentiation of vascular endothelial growth factor bioactivity, in vitro and in vivo, and high affinity binding to Flt-1 but not to Flk-1/ KDR. J. Biol. Chem. 269:25646-25654.

39. Millauer, B., L. K. Shawver, K. H. Plate, W. Risau, and A. Ullrich. 1994. Glioblastoma growth inhibited in vivo by a dominant-negative Flk-1 mutant. Nature (Lond.). 367:576-579.

40. Millauer, B., S. Wizigmann-Voos, H. Schnurch, R. Martinez, N. P. H. Moller, W. Risau, and A. Ullrich. 1993. High affinity VEGF binding and developmental expression suggest Flk-1 as a major regulator of vasculogenesis and angiogenesis. Cell. 72:835-846.

41. Pepper, M. S., N. Ferrara, L. Orci, and R. Montesano. 1992. Potent synergism between vascular endothelial growth factor and basic fibroblast growth factor in the induction of angiogenesis in vitro. Biochem. Biophys. Res. Commun. 189:824-831.

42. Goto, F., K. Goto, K. Weindel, and J. Folkman. 1993. Synergistic effects of vascular endothelial growth factor and basic fibroblast growth factor on the proliferation of bovine capillary endothelial cells within collagen gels. Lab. Invest. 69:508-517.

43. Falcone, D. J., T. A. McCaffrey, A. Haimovitz-Friedman, and M. Garcia. 1993. Transforming growth factor- $\beta 1$ stimulates macrophage urokinase expression and release of matrix-bound basic fibroblast growth factor. J. Cell. Physiol. 155:595-605.

44. Frater-Schroder, M., W. Risau, R. Hallmann, P. Gautschi, and P. Bohlen. 1987. Tumor necrosis factor $\alpha$, a potent inhibitor of endothelial cell growth in vitro, is angiogenic in vivo. Proc. Natl. Acad. Sci. USA. 84:5277-5281.

45. Sigegrist, W., S. Stutz, and A. N. Eberle. 1994. Homologous and heterologous regulation of $\alpha$-melanocyte stimulating hormone receptors in human and mouse melanoma cell lines. Cancer Res. 54:2604-2610. 